\title{
Salicylic acid and ethylene signaling pathways are involved in production of rice trypsin proteinase inhibitors induced by the leaf folder Cnaphalocrocis medinalis (Guenée)
}

\author{
WANG Xia, HU LiuCheng, ZHOU GuoXin, CHENG JiaAn \& LOU YongGen* \\ National Key Laboratory of Rice Biology, Institute of Insect Science, Zhejiang University, Hangzhou 310029, China
}

Received January 10, 2011; accepted May 11, 2011

\begin{abstract}
The roles of signaling pathways in the production of trypsin proteinase inhibitors (TrypPIs) in rice infested by the leaf folder (LF) Cnaphalocrocis medinalis were studied. Infestation by LF increased TrypPI levels in the leaves of rice plants at the tillering, booting and flowering stages but decreased TrypPI levels at the ripening stage; TrypPI levels in rice stems did not increase at any developmental stage. Infestation by LF at the tillering stage systemically increased TrypPI levels in leaves but not in stems; it also enhanced salicylic acid (SA) levels in leaves and stems, and the ethylene level released from plants. However, LF infestation did not increase JA concentrations. Exogenous application of SA or ethylene enhanced TrypPI levels in the leaves and stems of plants at the tillering stage, whereas treatment with both SA and ethylene induced lower levels of TrypPIs than treatment with SA or ethylene alone, suggesting an antagonistic effect of SA and ethylene on TrypPIs induction. The results suggest that both SA and ethylene signaling pathways are involved in the production of TrypPIs in rice induced by LF; moreover, the antagonistic effect of SA and ethylene may explain the changes in TrypPI levels seen at different plant developmental stages and in different organs.
\end{abstract}

rice, Cnaphalocrocis medinalis, jasmonic acid, salicylic acid, ethylene, trypsin proteinase inhibitor, herbivore-induced defense response

Citation: Wang X, Hu L C, Zhou G X, et al. Salicylic acid and ethylene signaling pathways are involved in production of rice trypsin proteinase inhibitors induced by the leaf folder Cnaphalocrocis medinalis (Guenée). Chinese Sci Bull, 2011, 56: 2351-2358, doi: 10.1007/s11434-011-4568-y

Plant proteinase inhibitors (PIs) are a group of small proteins, widespread in plants, with a molecular mass of between 8 and $20 \mathrm{kD}$. PIs are well known to reduce the growth of some lepidopteran and coleopteran larvae by inhibiting the activity of digestive enzymes in larval midguts [1-5]. Moreover, some plant PIs specifically inhibit the proteases of pathogens [6,7]. Therefore, PIs are regarded as an essential part of the plant's natural defense system against pests [8-10].

PIs can be induced by herbivore infestation, pathogen infection or mechanical wounding [11-16]. The induced PIs represent either local $[7,17]$ or systemic [18-21] responses, and either age-dependent [22] or organ-specific [8,18] traits. Application of chemical signals, such as jasmonic acid (JA),

*Corresponding author (email: yglou@zju.edu.cn) abscisic acid (ABA) and ethylene or salicylic acid (SA) can manipulate the production of PIs in plants [13,14,23,24], but the effects of each compound differ for different PIs. For example, mRNA levels of OSPIN (one of the PI genes found in rice) in rice plants were significantly up-regulated by $\mathrm{SA}, \mathrm{JA}$ and $\mathrm{H}_{2} \mathrm{O}_{2}$ but not by $\mathrm{ABA}$ and ethylene [25], whereas the expression levels of $O S B B P I$ were increased by JA and ethylene but inhibited by SA and ABA [12]. Thus, the induced PI levels in plants depend on cross-talk among multiple signaling pathways that are elicited by the herbivore.

Leaf folder (LF) Cnaphalocrocis medinalis (Guenée) is one of the most important rice pests. Because its larvae, which feed on the mesophyll cells of the leaf, cause a decrease in leaf area, the yield loss that results from infestation is dramatic [26]. Previous studies have shown that LF caterpillar infestation increases the levels of $\mathrm{SA}, \mathrm{H}_{2} \mathrm{O}_{2}$ and 
trypsin PIs (TrypPIs) but not JA in plants [27]. In contrast, LF caterpillar feeding induced lower TrypPI levels in rice as-lox mutants with low elicited JA levels than in wild-type plants, and the exogenous application of JA partially restored the induction of TrypPIs in as-lox mutants [28]. These results raise the question: which signaling pathways are responsible for the production of TrypPIs in rice induced by LF?

To answer this question, we first correlated the changes in LF-induced TrypPI levels with developmental stage in rice. Second, we measured local and systemic changes in levels of SA, JA and TrypPIs, and changes in the concentration of ethylene released from LF-infested plants. Finally, to determine if the exogenous application of chemical signals enhanced TrypPI levels in plants, we measured the TrypPI levels in plants treated with SA, ethylene, or both phytohormones.

\section{Materials and methods}

\subsection{Plant materials}

The rice cultivar Xiushui 11 was used in the experiments. Pregerminated seeds were sown in a greenhouse; after $20 \mathrm{~d}$, the seedlings were transplanted into small $(8 \mathrm{~cm}$ diameter $x$ $10 \mathrm{~cm}$ height, each with one plant) or large $(15 \mathrm{~cm}$ diameter $\times$ $10 \mathrm{~cm}$ height, each with 3 or 15 plants) clay pots. All plants were placed in a controlled climate room maintained at $28 \pm 2{ }^{\circ} \mathrm{C}, 70 \%-80 \% \mathrm{RH}$ (relative humidity), and $12 \mathrm{~h}$ photoperiod. Plants were watered daily and each pot was supplied with $10 \mathrm{~mL}$ nutrient solution (urea, $1 \mathrm{~g} \mathrm{~L}^{-1}$ ) every week. Plants were used for experiments 25-30 d after transplanting.

\subsection{Insects}

Leaf folder larvae in their first or second instars were captured in the field in Hangzhou, and then reared on Xiushui 11 rice plants. Third-instar larvae were used in the experiments.

\subsection{Plant treatments}

(i) LF treatment. Plants (one per pot) were individually infested at noon (12:00) with two third-instar larvae of LF that had been starved for $2 \mathrm{~h}$ and then placed on the leaves at nodes 3 and 4 (the youngest fully expanded leaf was defined as leaf node 1; thus, nodes 3 and 4 refer to the 3 rd and 4th fully expanded leaves, which are older than leaf node 1) (LF). Control plants (C) were not manipulated.

(ii) Mechanical wounding. Two leaves (at nodes 3 and 4) per plant (one per pot) were damaged by rolling a fabric pattern wheel over the leaf surface to create two rows of standardized puncture wounds (each row $18 \mathrm{~cm}$ long) on each leaf (W). Control plants were not manipulated (C).

(iii) SA treatment. Pots with one plant were used for the experiments. Plants were individually sprayed with $2 \mathrm{~mL}$ SA $\left(25,50\right.$ or $\left.100 \mu \mathrm{g} \mathrm{mL}^{-1}\right)$ in $50 \mathrm{mmol} / \mathrm{L}$ sodium phosphate buffer (titrated with $1 \mathrm{~mol} / \mathrm{L}$ citric acid to $\mathrm{pH} 8$, with $0.01 \%$ Tween) (SA). Controls were sprayed with $2 \mathrm{~mL}$ of the buffer (Buf).

(iv) Ethephon treatment. Plants (3 per pot) were enclosed in a sealed, transparent, plastic cage $(14 \mathrm{~cm}$ diameter $\times 55 \mathrm{~cm}$ height), after which $20 \mathrm{~mL}$ ethephon (SigmaAldrich, St Louis, MO, USA; 3 concentrations in MilliQ water, $\mathrm{pH}$ 7.2) was placed in the cage for $12 \mathrm{~h}$ (Eth). After $12 \mathrm{~h}$, the ethylene concentrations in the cages were determined using the method described below; concentrations were $0.034,0.039$ and $0.056 \mathrm{ppm}(1 \mathrm{ppm}=1 \mathrm{mg} / \mathrm{L})$, respectively, corresponding to the three ethephon concentrations. Controls were similarly treated with $20 \mathrm{~mL}$ distilled water (Water).

(v) SA+Eth treatment. Pots with 3 plants were used for the experiment. Plants were treated with SA $\left(50 \mu \mathrm{g} \mathrm{mL}^{-1}\right)$ and, after the SA solution had dried, with ethephon $(0.056$ ppm ethylene) for $12 \mathrm{~h}$ as described above (SA+Eth). Three groups of control plants were set up: (1) those treated with the buffer and, after the buffer dried, with ethephon (0.056 ppm ethylene) (Buf+Eth); (2) those treated with the buffer, and then with water (Buf+Water); and (3) control plants (C).

\subsection{JA and SA analysis}

Plants ( 1 per pot) were randomly assigned to 2 treatment groups, LF and C. The leaves at nodes 2, 3 and 5, and the leaf sheath corresponding to the leaf at node $3(3 \mathrm{~cm}$ in length) from each plant were harvested 0, 0.5, 1, 2, 4, 12, 24, or $48 \mathrm{~h}$ after the start of treatment. Each treatment at each time interval was replicated 5 times. Samples were immediately immersed in liquid nitrogen and stored at $-80^{\circ} \mathrm{C}$. Jasmonic acid and SA were extracted for gas chromatographymass spectrometry (GC-MS) analysis using labeled internal standards (328 ng D3-JA, kindly supplied by Ian T. Baldwin, Max Planck Institute of Chemical Ecology, Jena, Germany, and 345 ng D6-SA, by Cambridge Isotope Laboratory, Cambridge, MA, USA) as described by Lou and Baldwin [29].

\subsection{Ethylene determination}

Potted plants (15 per pot) were randomly assigned to 2 treatment groups, LF and C. Each pot was covered with a sealed, transparent, plastic cage $(14 \mathrm{~cm}$ diameter $\times 55 \mathrm{~cm}$ height). Ethylene production was determined by sampling $5 \mathrm{~mL}$ of headspace from the cage using a syringe at 2, 4, 6, $8,10,12,16,20,24,28$, and $32 \mathrm{~h}$ after the start of treatment. Each treatment was replicated 3 times. The ethylene sam- 
ples were analyzed by gas chromatography as described by Wang et al. [27].

\subsection{Effects of developmental stage of rice plants on induction of TrypPIs by LF}

Plants ( 1 per pot) at different developmental stages (tillering, booting, flowering or ripening) were randomly assigned to 2 treatment groups, LF and C. The leaf at node 3 and the leaf sheath corresponding to the leaf at node 3 ( $3 \mathrm{~cm}$ in length) from each plant were harvested on days 1,3 , and 5 after the start of treatment. Each treatment at each time interval was replicated 6 times. Samples were immediately immersed in liquid nitrogen and stored at $-80^{\circ} \mathrm{C}$ until TrypPI levels could be determined. TrypPI concentrations were measured by the radial diffusion assay as described by Lou and Baldwin [16] and expressed as nmol per mg of total protein.

\subsection{Local and systemic changes in TrypPI levels in rice plants infested by LF}

Plants (one per pot) were randomly assigned to 3 treatment groups: LF, W and C. The leaves at nodes 2, 3 and 5, and the leaf sheath (corresponding to the leaf at node 3$)(3 \mathrm{~cm}$ in length) from each plant were harvested on days 1,3 , and 5 after the start of treatment. Each treatment at each time interval was replicated 6 times. Samples were immediately immersed in liquid nitrogen and stored at $-80^{\circ} \mathrm{C}$ until TrypPI levels were determined.

\subsection{TrypPI levels in rice plants treated by $\mathrm{SA}$, ethephon, or both}

Plants ( 3 per pot) were randomly assigned to 8 treatment groups: SA $\left(25,50\right.$ or $\left.100 \mu \mathrm{g} \mathrm{mL}^{-1}\right)$, Buf, Eth $(0.034,0.039$ and $0.056 \mathrm{ppm}$ ), water, SA+Eth, Buf+Eth, Buf+water and C. The leaves at nodes 3 and 4 , and the corresponding leaf sheaths were harvested at days 1, 3, and 5 after the start of treatment (for SA+Eth, Buf+Eth, B+water and their corresponding controls, samples were harvested $3 \mathrm{~d}$ after treatment). Each treatment at each time interval was replicated six times. Samples were immediately immersed in liquid nitrogen and stored at $-80^{\circ} \mathrm{C}$ until TrypPI levels were determined.

\subsection{Data analysis}

Differences in JA, SA and ethylene production, and TrypPI levels in plants at different developmental stages were determined using Student's $t$-test. Other data were analyzed by one-way ANOVA; if the ANOVA analysis was significant $(P<0.05)$, Duncan's multiple range test was used to detect significant differences between groups. Data were analyzed using Statistica (Star Soft, Tulsa, OK, USA).

\section{Results}

\subsection{Effects of developmental stage of rice plants on induction of TrypPIs by LF}

Levels of TrypPIs in leaves and stems induced by LF depended on the plant's developmental stage (Figure 1). The level increased significantly in local leaves of plants at the tillering, booting or flowering stages when they were infested by LF, but decreased at the yellow ripening stage. In contrast, at all tested developmental stages, TrypPI levels in the stems of infested plants were lower than levels in the stems of non-infested plants, especially at the booting, flowering and yellow ripening stages.

\subsection{Local and systemic changes in TrypPI levels in rice plants infested by LF}

Levels of TrypPIs increased in infested leaves at node 3 on days 1,3 , and 5 after the start of treatment compared to those of control and mechanically wounded plants (Figure 2). TrypPI levels peaked on the third day following treatment (Figure 2(b)). Similar increases of TrypPI levels were found in the non-infested leaves at nodes 2 and 5 of infested plants. The levels of TrypPIs in the non-infested leaves at node 2 of infested plants significantly increased on days 3 and 5 after LF infestation compared to the levels in control and mechanically wounded plants (Figure 2(a)), and the levels of TrypPIs in leaves at node 5 only significantly

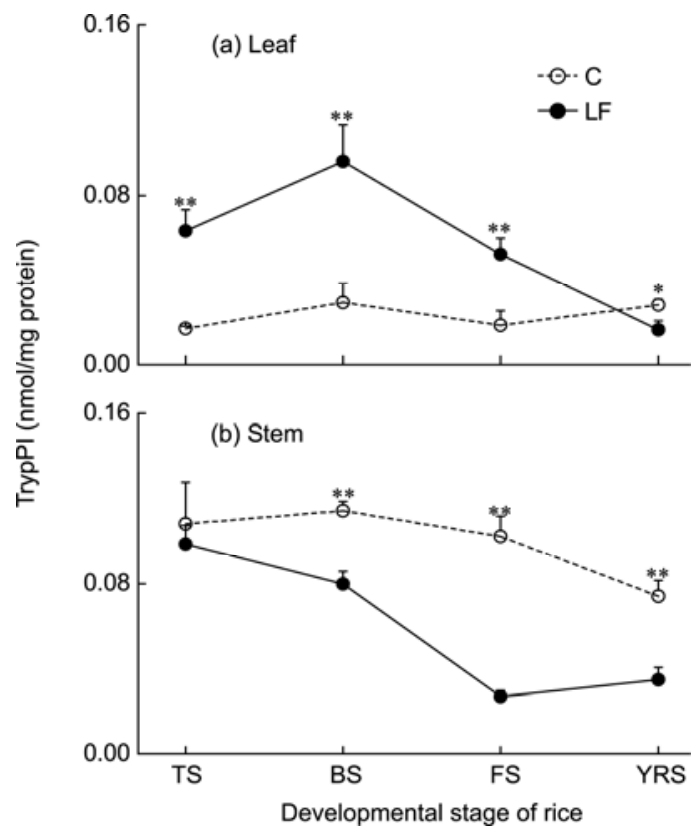

Figure 1 Mean (+SE) levels of TrypPIs at different developmental stages of rice plants infested by LF. (a) Leaf; (b) stem. C (control), non-manipulated plants; LF, plants infested by LF; TS, tillering stage; BS, booting stage; FS, flowering stage; YRS, yellow ripening stage. Asterisks indicate significant differences between $\mathrm{C}$ and LF at the same developmental stage (*, $P<0.05 ; * *, P<0.01$; Student's $t$-test). 

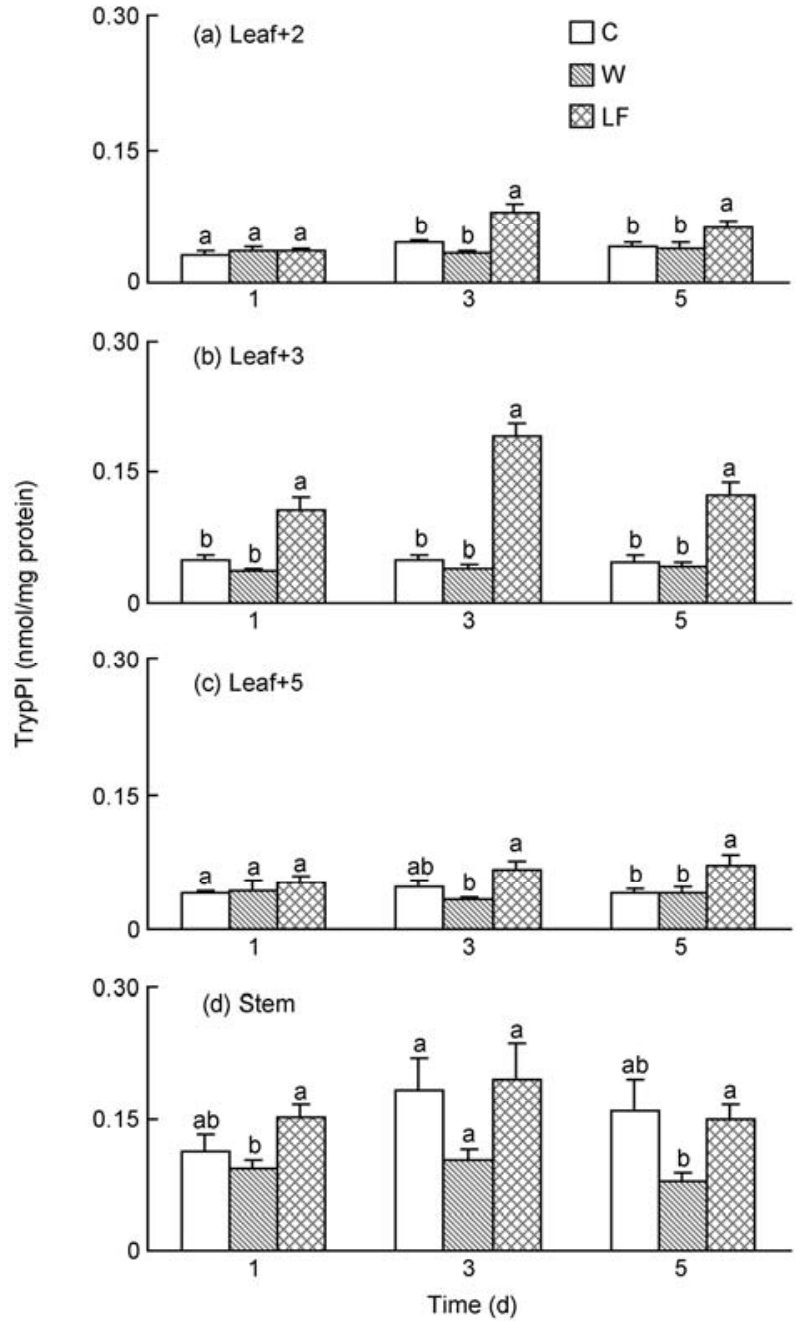

Figure 2 Mean (+SE) levels of TrypPIs in leaves and stems of rice plants infested by LF. (a) The leaf at node 2; (b) the leaf at node 3; (c) the leaf at node 5; (d) stem. C (control), non-manipulated plants; W, mechanically wounded plants; LF, plants infested by LF at nodes 3 and 4 . Letters indicate significant differences among treatments at the same treatment time $(P$ $<0.05$, Duncan's multiple range test)

increased by day 5 of the treatment (Figure 2(c)). There was no significant difference between TrypPI levels in leaves from control and mechanically wounded plants (Figure 2(a)-(c)).

Levels of TrypPIs in LF-infested plant stems were significantly higher than those in mechanically wounded plants but not in control plants at days 1 and 5 after treatment (Figure 2(d)).

\subsection{Changes in JA, SA and ethylene levels of rice plants infested by $\mathbf{L F}$}

Levels of JA in LF-infested plants were not higher than those in control plants (Figure 3). In contrast, JA levels were significantly decreased in some leaves of infested plants, namely the infested leaves (at node 3 ) at $2 \mathrm{~h}$ and the non-infested leaves at node 5 at $1 \mathrm{~h}$ after the start of treatment (Figure 3).
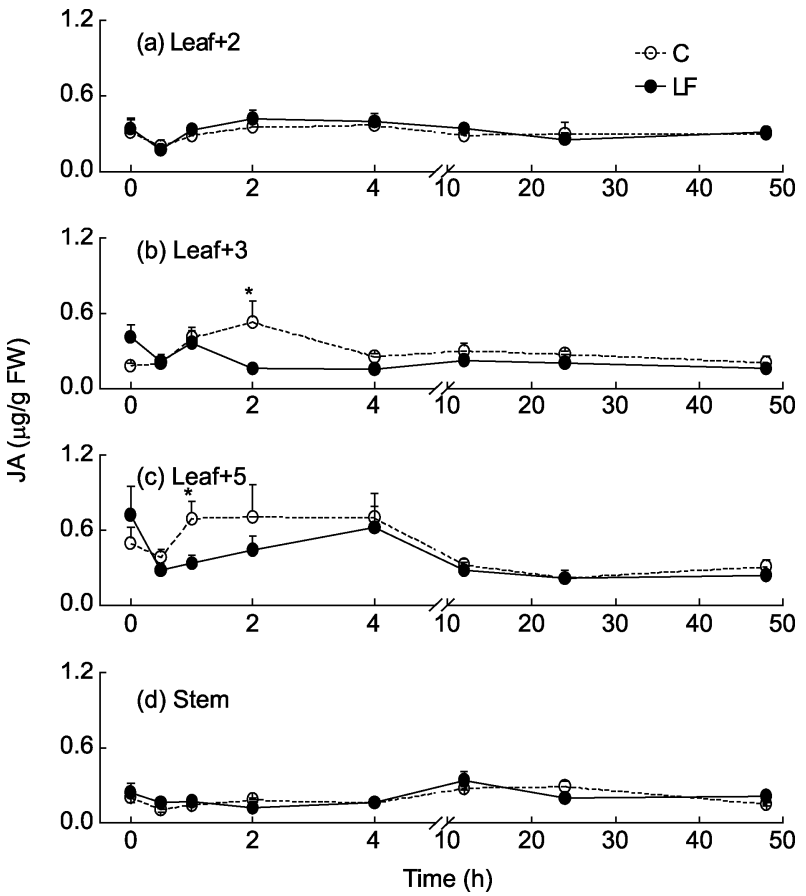

Figure 3 Mean (+SE) levels of JA in leaves and stems of rice plants infested by LF. (a) The leaf at node 2; (b) the leaf at node 3; (c) the leaf at node 5; (d) stem. C (control), non-manipulated plants; LF, plants infested by $\mathrm{LF}$ at nodes +3 and +4 . Asterisks indicate significant differences between $\mathrm{C}$ and LF at the same treatment time (*, $P<0.05 ; * *, P<0.01$; Student's $t$-test).

Infestation by LF increased the levels of SA in rice plants, depending on the timing of measurements during treatment (Figure 4). Levels of SA in infested leaves at node 3
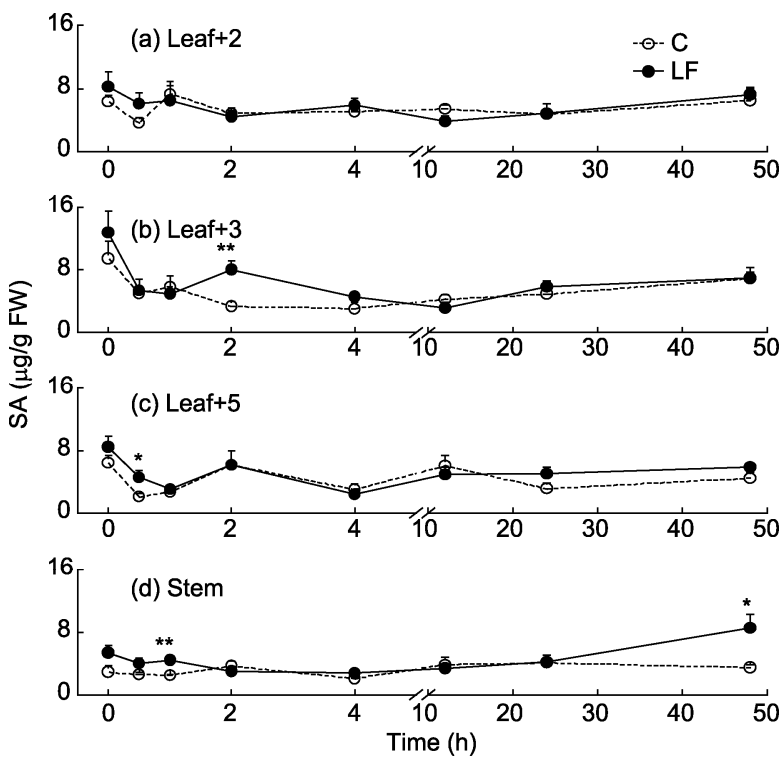

Figure 4 Mean $(+\mathrm{SE})$ levels of SA in leaves and stems of rice plants infested by LF. (a) The leaf at node 2; (b) the leaf at node 3; (c) the leaf at node 5; (d) stem. C (control), non-manipulated plants; LF, plants infested by $\mathrm{LF}$ at nodes +3 and +4 . Asterisks indicate significant differences between $\mathrm{C}$ and $\mathrm{LF}$ at the same treatment time $(*, P<0.05$; **, $P<0.01$; Student's $t$-test). 
significantly increased at $2 \mathrm{~h}$ after treatment when compared to SA levels in control plants (Figure 4(b)). Similarly, in non-infested leaves at node 5 of the infested plants, SA levels were significantly increased at $0.5 \mathrm{~h}$ after treatment (Figure 4(c)). However, in leaves at node 2, the levels of SA were not as drastically altered as those in leaves of control plants (Figure 4(a)). In stems, LF infestation also significantly increased the levels of SA at $1 \mathrm{~h}$ after treatment (Figure 4(d)).

Significant increases in ethylene levels in LF-infested plants compared to non-infested plants were observed 2 to $32 \mathrm{~h}$ after treatment (Figure 5). Because the container was airtight, levels of ethylene in the container increased with treatment time.

\subsection{TrypPI levels in rice plants treated with $\mathrm{SA}$, eth- ylene or both}

Levels of TrypPIs in SA-treated rice plants were enhanced compared to levels in plants in treatment groups Buf and C, depending on the SA concentration and plant tissue sampled (Figure 6). In leaves, $50 \mu \mathrm{g} \mathrm{mL}^{-1} \mathrm{SA}$ solution significantly enhanced TrypPI levels on days 1 and 3 after treatment, yet $100 \mu \mathrm{g} \mathrm{mL}^{-1} \mathrm{SA}$ significantly increased TrypPI levels only at day 3 ; in contrast, $25 \mu \mathrm{g} \mathrm{mL}^{-1} \mathrm{SA}$ had no effect on TrypPI levels (Figure 6(a)). In stems, $25 \mu \mathrm{g} \mathrm{mL}^{-1} \mathrm{SA}$ treatment increased TrypPI levels at day 1 after treatment and $50 \mu \mathrm{g} \mathrm{mL}^{-1} \mathrm{SA}$ increased TrypPI levels at day 3 , but 100 $\mu \mathrm{g} \mathrm{mL}^{-1} \mathrm{SA}$ had no effect (Figure 6(b)).

Ethephon treatment also increased the levels of TrypPIs in the leaves of rice plants, and the induced TrypPI levels were positively correlated with the concentration of applied ethylene (Figure 7(a)). For stems, only treatment with 0.056 ppm ethylene significantly enhanced TrypPI levels $5 \mathrm{~d}$ after treatment (Figure 7(b)). Treatment with 0.034 ppm ethylene decreased TrypPI levels in stems at day 1 after treatment.

Similarly, the levels of TrypPIs in leaves treated with Buf $+0.056 \mathrm{ppm}$ Eth increased compared to the levels of TrypPIs in control leaves or in leaves treated with Buf+

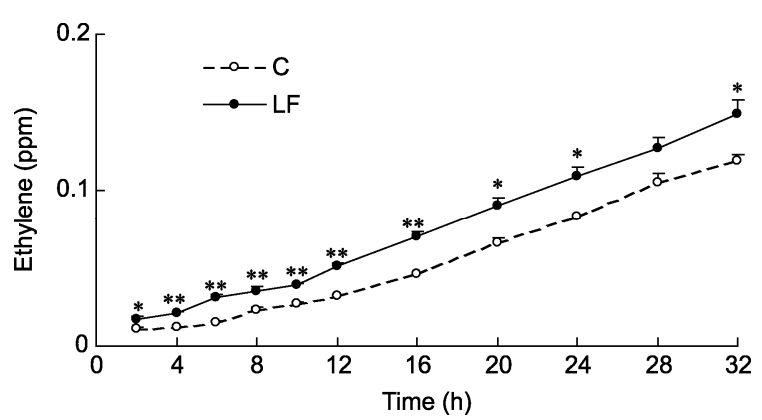

Figure 5 Mean (+SE) levels of ethylene released from rice plants infested by LF. C (control), non-manipulated plants; LF, plants infested by LF at nodes 3 and 4 . Asterisks indicate significant differences between $\mathrm{C}$ and LF at the same treatment time $(*, P<0.05 ; * *, P<0.01$; Student's $t$-test $)$

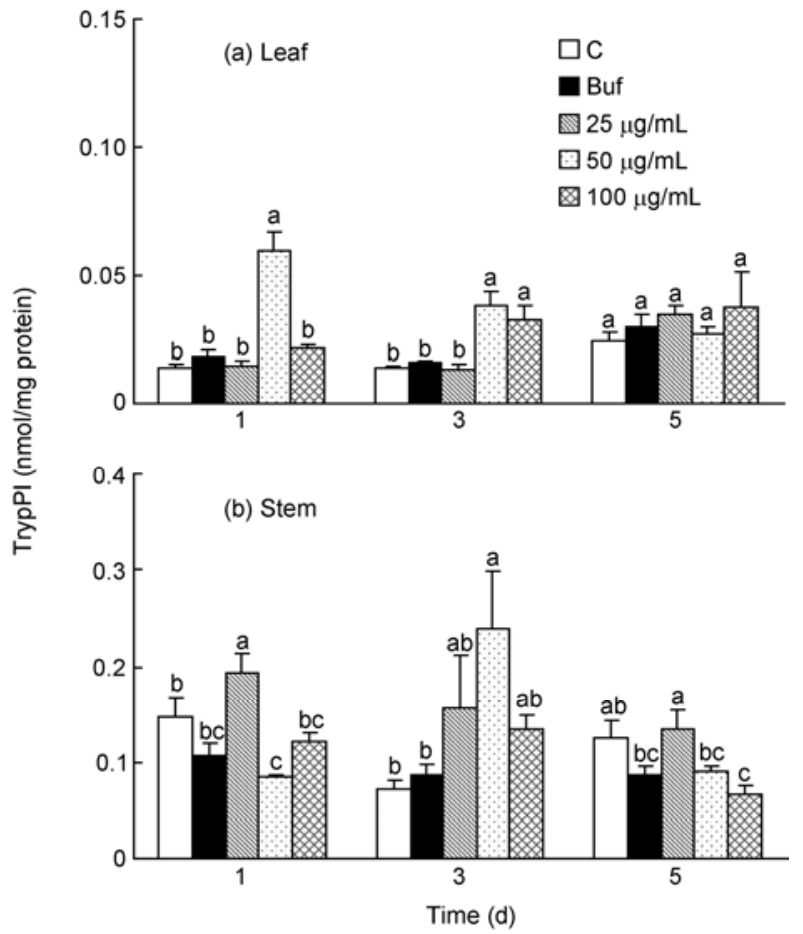

Figure 6 Mean (+SE) levels of TrypPIs in leaves and stems of rice plants treated by SA. (a) Leaf; (b) stem. C (control), non-manipulated plants; Buf, plants individually treated with $2 \mathrm{~mL}$ of $50 \mathrm{mmol} / \mathrm{L} \mathrm{Na}_{2} \mathrm{HPO}_{4}$ buffer $(\mathrm{pH}$ 8.0); $25 \mu \mathrm{g} \mathrm{mL}^{-1}$, plants individually treated with $2 \mathrm{~mL}$ of $25 \mu \mathrm{g} \mathrm{mL}^{-1} \mathrm{SA}$; $50 \mu \mathrm{g} \mathrm{mL}^{-1}$, plants individually treated with $2 \mathrm{~mL}$ of $50 \mu \mathrm{g} \mathrm{mL}^{-1} \mathrm{SA} ; 100$ $\mu \mathrm{g} \mathrm{mL}{ }^{-1}$, plants individually treated with $2 \mathrm{~mL}$ of $100 \mu \mathrm{g} \mathrm{mL}^{-1} \mathrm{SA}$. Letters indicate significant differences among treatments at the same treatment time $(P<0.05$, Duncan's multiple range test).

Water (Figure 7(c)). However, there was no difference between TrypPI levels in the leaves of plants treated with SA $\left(50 \mu \mathrm{g} \mathrm{mL}^{-1}\right)+$ Eth $(0.056 \mathrm{ppm})$ and of plants treated with Eth (Buf+Eth) alone. In stems, treatment with SA $\left(50 \mu \mathrm{g} \mathrm{mL}^{-1}\right)$ + Eth $(0.056 \mathrm{ppm})$ did not increase TrypPI levels more than in control plants or those treated with Buf+Water.

\section{Discussion}

The systemic induction of herbivore-induced defense responses, including changes in levels of volatile and nonvolatile chemicals, has been reported in many plant species, such as tomato and Nicotiana attenuata [30]. Similarly, we found that LF infestation resulted in a systemic increase of TrypPI levels in the leaves of rice plants at the tilling stage, and this response was more rapid and stronger in young leaves than in old leaves (Figure 2). However, LF infestation did not enhance the levels of TrypPIs in rice stems at the tillering stage, though it decreased the levels in stems at the booting, flowering and yellow ripening stages (Figures 1 and 2). This indicates that induction of TrypPIs in rice plants by LF infestation is in part systemic and transportation of the wound signals follows source-sink relationships, moving 

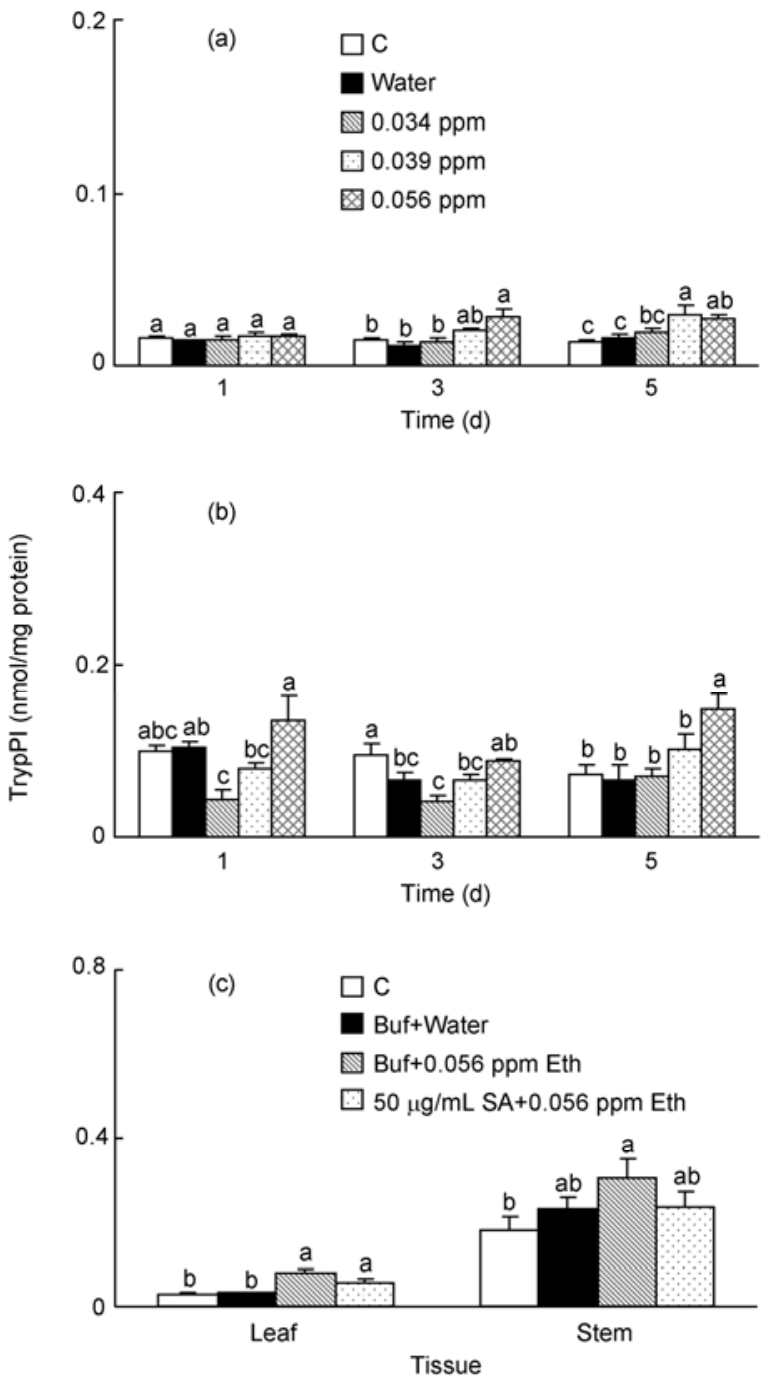

Figure 7 Mean (+SE) levels of TrypPIs in rice plants treated with ethephon, SA or both. (a, b) levels of TrypPIs in leaves (a) or stems (b) of plants treated with ethephon; (c) levels of TrypPIs in leaves and stems of plants treated with SA, ethephon or both. $\mathrm{C}$ (control), non-manipulated plants; Water, plants fumigated with $20 \mathrm{~mL}$ of $\mathrm{ddH}_{2} \mathrm{O} ; 0.034 \mathrm{ppm}$, plants fumigated with $20 \mathrm{~mL}$ ethephon solution in a plastic cage resulting in $0.034 \mathrm{ppm}$ ethylene in the cage $12 \mathrm{~h}$ after treatment; $0.039 \mathrm{ppm}$, plants fumigated with $20 \mathrm{~mL}$ ethephon solution in a plastic cage resulting in $0.039 \mathrm{ppm}$ ethylene in the cage $12 \mathrm{~h}$ after treatment; $0.056 \mathrm{ppm}$, plants fumigated with $20 \mathrm{~mL}$ ethephon solution in a plastic cage resulting in $0.056 \mathrm{ppm}$ ethylene in the cage $12 \mathrm{~h}$ after treatment. Buf+Water, plants first individually treated with $2 \mathrm{~mL}$ of $50 \mathrm{mmol} / \mathrm{L} \mathrm{Na}_{2} \mathrm{HPO}_{4}$ buffer ( $\mathrm{pH} 8.0$ ) and then fumigated with $20 \mathrm{~mL}$ of $\mathrm{ddH}_{2} \mathrm{O}$; Buf $+0.056 \mathrm{ppm}$ Eth, plants first individually treated with $2 \mathrm{~mL}$ of $50 \mathrm{mmol} / \mathrm{L} \mathrm{Na}_{2} \mathrm{HPO}_{4}$ buffer $(\mathrm{pH} 8.0)$ and then fumigated with $20 \mathrm{~mL}$ ethephon solution resulting in $0.056 \mathrm{ppm}$ ethylene in the cage $12 \mathrm{~h}$ after treatment; $50 \mu \mathrm{g} \mathrm{mL}^{-1} \mathrm{SA}+0.056 \mathrm{ppm}$ Eth: plants first individually treated with $2 \mathrm{~mL}$ of $50 \mu \mathrm{g} \mathrm{mL} \mathrm{L}^{-1} \mathrm{SA}$ and then fumigated with $20 \mathrm{~mL}$ ethephon solution resulting in $0.056 \mathrm{ppm}$ ethylene in the cage $12 \mathrm{~h}$ after treatment. Letters indicate significant differences among treatments at the same treatment time $(P<0.05$, Duncan's multiple range test).

in the phloem together with sucrose [13].

It is well documented that herbivore infestation may elicit JA, SA and ethylene signaling pathways in plants; moreover, these pathways are known to play an important role in shaping plant defense responses [16,31]. In this study, we found that LF infestation increased SA and ethylene levels in rice plants, but, surprisingly, decreased JA levels (Figures 3-5). This indicates that LF infestation activates the SA and ethylene signaling pathways but not the JA signaling pathway in rice plants, which is different from other chewing herbivores whose infestation generally activates the JA-mediated pathway in plants [30,32]. It is reported that SA suppresses JA accumulation and signaling in several plant species, such as Arabidopsis, N. attenuata and rice $[33,34]$. Thus, the decrease in JA levels in LF-infested rice plants might be because of an increase in SA levels. Unlike some chewing herbivores, LF larvae feed only on the epidermis of the leaves; this behavior damages plants less than if entire leaves are browsed. Whether non-activa- tion of the JA signaling pathway in plants infested by LF is related to the feeding habits of LF remains to be elucidated.

Like TrypPI levels, SA levels in plants infested by LF were also systemically increased (Figure 4). In addition, much higher levels of ethylene were released in LF-infested plants than in control plants (Figure 5); the compound might be airborne or transported through the plant. The exogenous application of SA or ethylene at appropriate concentrations to rice plants enhanced the levels of TrypPIs in leaves and stems (Figures 6 and 7). Furthermore, treatment with both SA and ethylene resulted in relatively lower levels of TrypPIs in leaves and stems than treatment with SA or ethylene alone, and TrypPI levels in stems were similar to those of controls (C or Buf+Water) (Figure 7(c)). This indicates that both SA and ethylene signaling pathways are involved in the production of TrypPIs in rice induced by LF. The data also imply that SA and ethylene play antagonistic roles in the induction of TrypPIs in rice plants, particularly in rice stems. The antagonistic effect between SA and ethylene on the production of total TrypPIs in rice might result from the induction of the two opposing signal molecules on the same TrypPI; this is the case for OsBBPI, whose mRNA levels were increased by ethylene but inhibited by SA [12]. On the other hand, SA and ethylene may enhance the levels of the same TrypPI through two pathways that work in opposition to one another. Thus, plants treated with both SA and ethylene may have lower levels of TrypPIs than those treated with SA or ethylene alone. The antagonistic effect of SA and ethylene on the induction of TrypPIs may explain why LF infestation did not enhance TrypPI levels in the stems of plants (Figures 1 and 2).

As reported in other plants, for example, $N$. attenuata [13] and $N$. plumbaginifolia [35], the developmental stage of rice plants also influenced the degree to which TrypPIs were inducible by LF (Figure 1). Compared to those in non-infested plants, for example, TrypPI levels in infested leaves were significantly increased at the tillering, booting or flowering stages of plants, whereas levels were decreased at the ripening stage (Figure 1). Changes in the inducibility of TrypPIs in leaves or stems at different developmental stages 
might be related to plant energy allocation [13]. For instance, at the ripening stage, most of a plant's energy has been allocated to production; therefore little energy remains for defense responses, which cause the levels of TrypPIs in leaves to increase or decrease. Plant energy allocation is a complex physiological process in which phytohormones play an important role [36]. On the other hand, constitutive and elicited levels of phytohormones, such as JA, SA and ET, change with plant developmental stage [37-39]. Therefore, changes in the inducibility of TrypPIs in rice leaves or stems at different developmental stages may be shaped by interactions among plant hormones, such as SA and ethylene. The relative amount of SA and ethylene in tissues or organs, and the sensitivity of the tissues or organs to SA and ethylene, might change with developmental stage, resulting in changes in the inducibility of TrypPIs.

In summary, LF infestation elicited SA and ethylene signaling pathways in rice, both of which, through crosstalk, manipulated the production of TrypPIs in plants. The levels of SA and ethylene in tissues or organs, the sensitivity of the tissues or organs to SA and ethylene, and the antagonistic effect of SA and ethylene on the induction of TrypPIs all influenced the production of TrypPIs in LFinduced rice plants. The interaction of these factors determined the levels of LF-induced TrypPIs in different tissues and organs and at different developmental stages.

We thank Emily Wheeler for her invaluable editorial assistance. This work was supported by the National Basic Research Program of China (2010CB126200), the Innovation Research Team Program of the National Natural Science Foundation of China (31021003), and the earmarked fund for Modern Agro-industry Technology Research System.

1 Macedo M L R, Mello G C, Freire M D G, et al. Effect of a trypsin inhibitor from Dimorphandra mollis seeds on the development of Callosobruchus maculatus. Plant Physiol Biochem, 2002, 40: 891898

2 Tamhane V A, Chougule N P, Giri A P, et al. In vivo and in vitro effect of Capsicum annum proteinase inhibitors on Helicoverpa armigera gut proteinases. Biochim Biophys Acta, 2005, 1722: 156-167

3 Franco O L, Dias S C, Magalhaes C P, et al. Effects of sovbean Kunitz trypsin inhibitor on the cotton boll weevil (Anthonomus grandis). Phytochemistry, 2004, 65: 81-89

4 Bhattacharyya A, Leighton S M, Babu C R. Bioinsecticidal activity of Archidendron ellipticum trypsin inhibitor on growth and serine digestive enzymes during larval development of Spodoptera litura. Comp Bioch Phys C, 2007, 145: 669-677

5 Zhu Y C, Abel C A, Chen M S. Interaction of Cry1Ac toxin (Bacillus thuringiensis) and proteinase inhibitors on the growth, development, and midgut proteinase activities of the bollworm, Helicoverpa zea. Pestic Biochem Phys, 2007, 87: 39-46

6 Geoffroy P, Legrand M, Fritig B. Isolation and characterization of a proteinaceous inhibitor of microbial proteinases induced during the hypersensitive reaction of tobacco to tobacco mosaic virus. Mol Plant Microbe Interact, 1990, 3: 327-333

7 Balandin T, Vanderdoes C, Albert J M B, et al. Structure and induction pattern of a novel proteinase inhibitor class II gene of tobacco. Plant Mol Biol, 1995, 27: 1197-1204

8 Qu L J, Chen J, Liu M H, et al. Molecular cloning and functional analysis of a novel type of Bowman-Birk inhibitor gene family in rice.
Plant Physiol, 2003, 133: 560-570

9 Hermosa M R, Turrà D, Fogliano V, et al. Identification and characterization of potato protease inhibitors able to inhibit pathogenicity and growth of Botrytis cinerea. Physiol Mol Plant Pathol, 2006, 68: 138-148

10 Oliveira A S, Migliolo L, Aquino R O, et al. Purification and characterization of a trypsin-papain inhibitor from Pithecelobium dumosum seeds and its in vitro effects towards digestive enzymes from insect pests. Plant Physiol Biochem, 2007, 45: 858-865

11 Cordero M J, Raventos D, Sansegundo B. Expression of a maize proteinase-inhibitor gene is induced in response to wounding and fungal infection: Systemic wound-response of a monocot gene. Plant J, 1994, 6: 141-150

12 Rakwal R, Agrawal G K, Jwa N S. Characterization of a rice (Oryza sativa L.) Bowman-Birk proteinase inhibitor: Tightly light regulated induction in response to cut, jasmonic acid, ethylene and protein phosphatase 2A inhibitors. Gene, 2001, 263: 189-198

13 Van Dam N M, Horn M, Mares M, et al. Ontogeny constrains systemic protease inhibitor response in Nicotiana attenuata. J Chem Ecol, 2001, 27: 547-568

14 Casaretto J A, Zuniga G E, Corcuera L J. Abscisic acid and jasmonic acid affect proteinase inhibitor activities in barley leaves. J Plant Physiol, 2004, 161: 389-396

15 Lou Y G, Baldwin I T. Nitrogen supply influences herbivore-induced direct and indirect defenses and transcriptional responses to Nicotiana attenuata. Plant Physiol, 2004, 135: 496-506

16 Lou Y G, Baldwin I T. Silencing of a germin-like gene in Nicotiana attenuata improves performance of native herbivores. Plant Physiol, 2006, 140: 1126-1136

17 Jongsma M A, Bakker P L, Visser B, et al. Trypsin inhibitor activity in mature tobacco and tomato plants is mainly induced locally in response to insect attack, wounding and virus infection. Planta, 1994, 195: 29-35

18 Pearce G, Johnson S, Ryan C A. Purification and characterization from tobacco (Nicotiana tabacum) leaves of six small, wound-inducible, proteinase isoinhibitors of the potato inhibitor II family. Plant Physiol, 1993, 102: 639-644

19 Ohto M, Nakamurakito K, Nakamura K. Induction of expression of genes coding for sporamin and beta-amylase by polygalacturonic acid in leaf-petiole cuttings of sweet potato. Plant Physiol, 1992, 99: 422-427

20 Orians C M, Pomerleau J, Ricco R. Vascular architecture generates fine scale variation in systemic induction of proteinase inhibitors in tomato. J Chem Ecol, 2000, 26: 471-485

21 Wang S J, Lan Y C, Chen S F, et al. Wound-response regulation of the sweet potato sporamin gene promoter region. Plant Mol Biol, 2002, 48: 223-231

22 Botella M A, Xu Y, Prabha T N, et al. Differential expression of soybean cysteine proteinase inhibitor genes during development and in response to wounding and methyl jasmonate. Plant Physiol, 1996, 112: $1201-1210$

23 O'Donnell P J, Calvert C, Atzorn R, et al. Ethylene as a signal mediating the wound response of tomato plants. Science, 1996, 274: 1914-1917

24 Botelho-Júnior S, Siqueira-Júnior C L, Jardim B C, et al. Trypsin inhibitors in passion fruit (Passiflora f. edulis flavicarpa) leaves: Accumulation in response to methyl jasmonate, mechanical wounding, and herbivory. J Agric Food Chem, 2008, 56: 9404-9409

25 Agrawal G K, Rakwal R, Jwa N S, et al. Oryza sativa proteinase inhibitor gene, OsPIN, whose mRNA specifically accumulates in a compatible host-blast pathogen interaction. Plant Physiol Biochem, 2002, 40: 175-182

26 Ding J H. Agricultural Emtomology (in Chinese). Nanjing: Jiangsu Scientific and Technological Press, 1991

27 Wang X, Lu Y H, Wang X, et al. Influence of infestation by rice leaf folder Cnaphalocrocis medinalis on levels of defense chemicals and signal moleculars. J Zhejiang Univ, 2008, 34: 532-539

28 Zhou G X, Qi J F, Ren N, et al. Silencing OsHI-LOX makes rice more susceptible to chewing herbivores, but enhances resistance to a 
phloem feeder. Plant J, 2009, 60: 638-648

29 Lou Y, Baldwin I T. Manduca sexta recognition and resistance among allopolyploid Nicotiana host plants. Proc Natl Acad Sci USA, 2003, 100: 14581-14586

30 Howe G A, Jander G. Plant immunity to insect herbivores. Annu Rev Plant Biol, 2008, 59: 41-66

31 Wu J Q, Hettenhausen C, Meldau S, et al. Herbivory rapidly activates MAPK signaling in attacked and unattacked leaf regions but not between leaves of Nicotiana attenuata. Plant Cell, 2007, 19: 1096-1122

32 Bostock R M. Signal crosstalk and induced resistance: Straddling the line between cost and benefit. Annu Rev Phytopath, 2005, 43: 545-580

33 Lee A, Cho K, Jang S, et al. Inverse correlation between jasmonic acid and salicylic acid during early wound response in rice. Biochem Biophys Res Comm, 2004, 318: 734-738
34 Wu J Q, Baldwin I T. Herbivory-induced signalling in plants: Perception and action. Plant Cell Environ, 2009, 32: 1161-1174

35 Ausloos G R J, Proost P, Vandamme J, et al. Proteinase inhibitor II is developmentally regulated in Nicotiana flowers. Physiol Plantarum, 1995, 94: 701-707

36 Matyssek R, Agerer R, Ernst D, et al. The plant's capacity in regulating resource demand. Plant Biol, 2005, 7: 560-580

37 Herbers K, Meuwly P, Metraux J P, et al. Salicylic acid-independent induction of pathogenesis-related protein transcripts by sugars is dependent on leaf developmental stage. FEBS Lett, 1996, 397: 239-244

38 Ohnmeiss T E, Baldwin I T. Optimal defense theory predicts the ontogeny of an induced nicotine defense. Ecology, 2000, 81: 1765-1783

39 Alexander L, Grierson D. Ethylene biosynthesis and action in tomato: A model for climacteric fruit ripening. J Exp Bot, 2002, 53: 20392055

Open Access This article is distributed under the terms of the Creative Commons Attribution License which permits any use, distribution, and reproduction in any medium, provided the original author(s) and source are credited. 